Juan Pablo Hourcade, The Interactions website linteractions.acm.org) hosts a stable of bloggers who
University of lowa $\begin{aligned} & \begin{array}{l}\text { share insights and observations on HCl, often challenging current practices. Each } \\ \text { issue we'll publish selected posts from some of the leading voices in the field. }\end{array}\end{aligned}$

\title{
Violent Groups, Social Psychology, and Computing
}

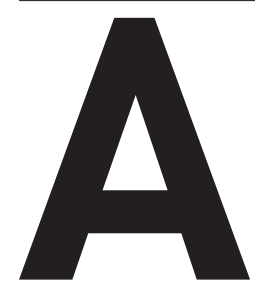

bout two years

ago, I participated

in the first Build

Peace conference

[1], a meeting

of practitioners

and researchers

from a wide range of backgrounds with a common interest in using technologies to promote peace around the world. During one session, the presenter asked members of the audience to raise their hands if they had lived in multiple countries for an extended period of time. Most hands in the audience went up, which was at the same time a surprise and a revelation. Perhaps there is something about learning to see the world from another perspective that can lead us to view our common humanity as more binding than group allegiances.

It's not that group allegiances are necessarily negative. They can be very useful for working together toward common goals. Moreover, most groups use peaceful methods toward constructive goals. The problems come when strong group allegiances intersect with ideologies where violence is a widely accepted method, with a goal of dominion over (or elimination of) other groups.

A recent issue of Scientific American Mind magazine [2] with several articles on terrorism highlights risk factors associated with participation in groups that support the use of violence against other groups. A consistent theme is the strong sense of belonging to a particular group to the exclusion of other groups, in some cases including family and childhood friends, together with viewing those from other groups as outsiders to be ignored or worse.

Information filters or bubbles can

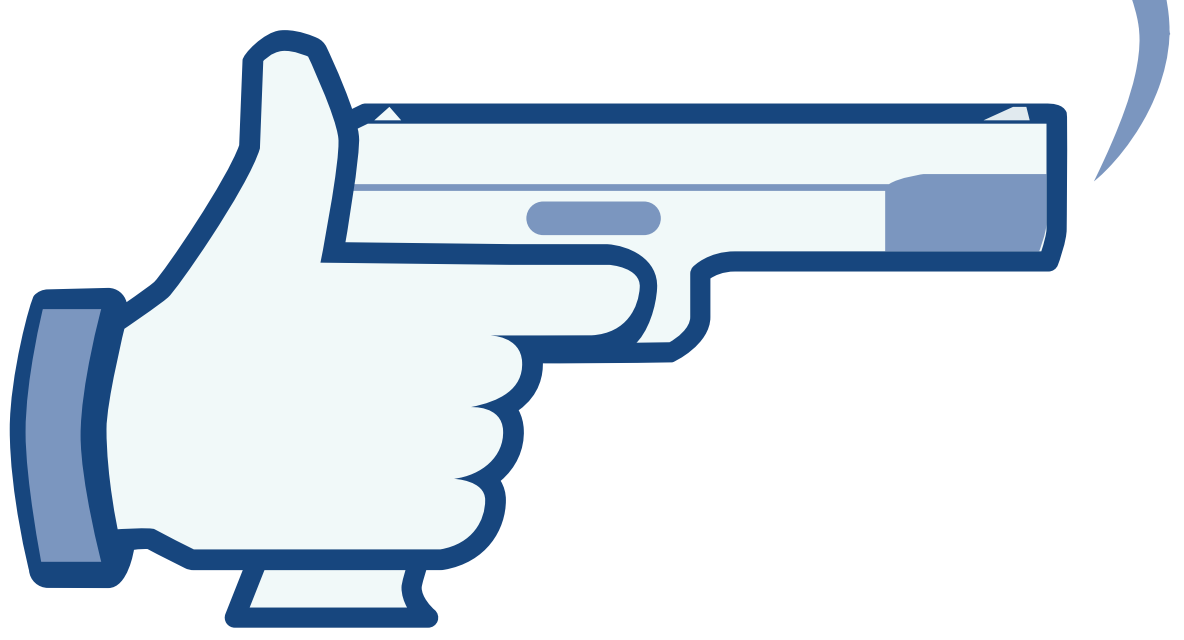

play a role in isolating people so they deeply engage with the viewpoints of mostly just one group, and can validate extreme views toward people outside that community. These filters and bubbles are not new to the world of social media but they are easily realized within it, as competing services attempt to grab our attention by providing us with content we are more likely to enjoy.

At the same time, interactive technology and social media can be the remedy to break out of these filters and bubbles. To think about what some of these remedies might be, I refer to some articles that can provide motivation, all cited in the previously mentioned Scientific American Mind issue $[2,3]$.

The first area in which interactive technologies could help is in making us avoid the "false consensus effect"
[4], through which we often believe that our personal judgements are common among others. Perhaps providing a sense of the relative commonality (or rarity) of certain beliefs could be useful.

Sometimes we may not have strong feelings about something. If that is the case, we tend to copy the decisions of others we feel resemble us while disregarding the views of those who are different [5]. In this case, it's important to be exposed to experts from outside our group, who may help us realize that people from other groups often make decisions that would work for us too.

Allegiances to groups can get to the point of people being willing to die for their group when they feel their identity is fused with that of the group [6]. Interactive technologies could help in this regard by making it easier 
to identify with multiple groups, so we don't feel associated with just one.

As I mentioned earlier, being part of a tight group most of the time does not lead to problems, and can often be useful. But what if the group widely accepts the use of violence to achieve dominance over others? One way to bring people back from these groups is to reconnect them with memories and emotions of their earlier life, helping them reunite with family and old friends [7]. Social media already does a good job of this, but perhaps there could be a way of highlighting the positives from the past in order to help. With a bit of content analysis, it would be possible to focus on the positive highlights.

\section{ENDNOTES}

1. http://howtobuildpeace.org/bp2014/

2. Walls, C. Beyond fear: The psychology of terrorism. Scientific American Mind 27, 3 (2016), 32-49.

3. Dutton, K. and Abrams, D. Extinguishing the threat. Scientific American Mind 27, 3 (2016), 44-49.

4. Ross, L., Greene, D., and House, P. The "false consensus effect": An egocentric bias in social perception and attribution processes. Fournal of Experimental Social Psychology 13, 3 (1977), 279-301.

5. Abrams, D., Wetherell, M., Cochrane, S., Hogg, M.A., and Turner, J.C. Knowing what to think by knowing who you are: Self-categorization and the nature of norm formation, conformity and group polarization. British Fournal of Social Psychology 29, 2 (1990), 97-119.

6. Swann, W.B., Gómez, Á., Dovidio, J.F., Hart, S., and Jetten, J. Dying and killing for one's group identity fusion moderates responses to intergroup versions of the trolley problem. Psychological Science 21, 8 (2010), 1176-1183.

7. Bouzar, D. Escaping radicalism. Scientific American Mind 27, 3 (2016), 40-43.

(1) Juan Pablo Hourcade is an associate professor in the Department of Computer Science at the University of lowa. His research focuses on the design, implementation, and evaluation of technologies that support creativity, collaboration, well-being, healthy development, and information access for a variety of users, including children and older adults.

$\rightarrow$ juanpablo-hourcadeduiowa.edu

(2) http://interactions.acm.org/blog/ author/7263/Juan\%20Pablo\%20Hourcade

DOI: $10.1145 / 3002118$

COPYRIGHT HELD BY AUTHOR

\title{
ACM LEARNING CENTER
}

\author{
RESOURCES \\ FOR LIFELONG LEARNING
}

learning.acm.org

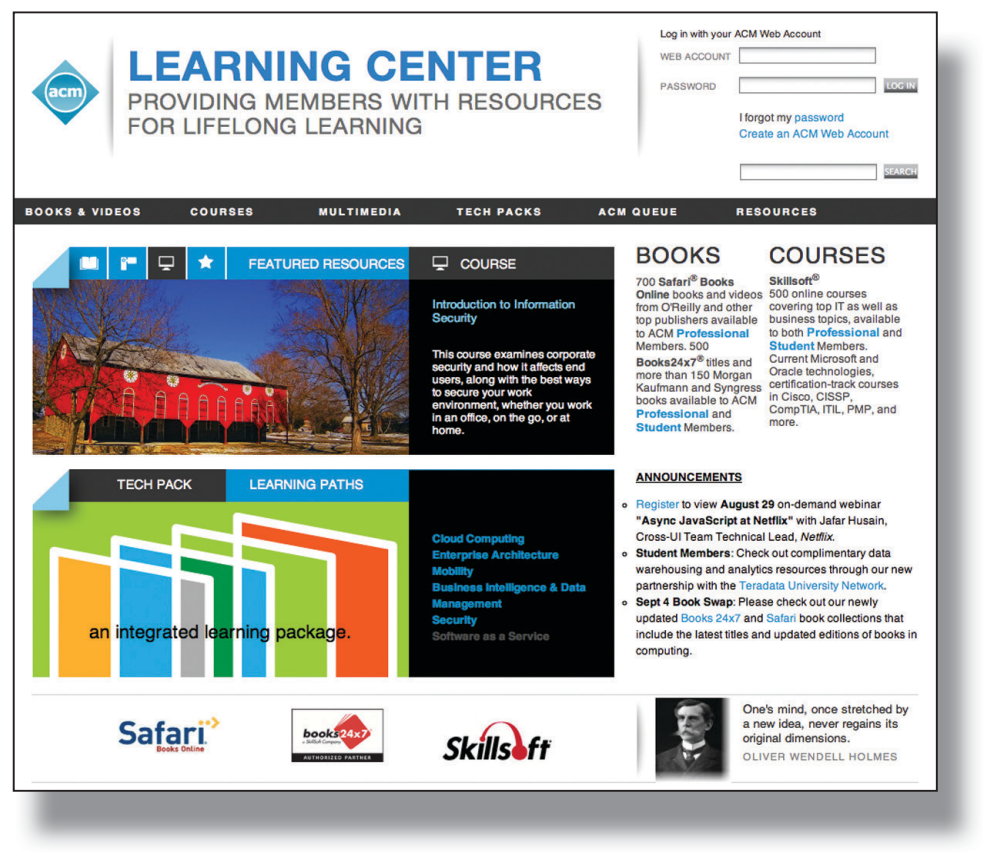

Online Courses from Skillsoft

\section{Online Books from Safari, Books24x7, Morgan Kaufmann and Syngress}

\section{Webinars on today's hottest topics in computing}

